\title{
Identificación genética de aislamientos de Colletotrichum spp. causantes de antracnosis en frutos de aguacate, banano, mango y tomate de árbol
}

\author{
Lederson Gañán ${ }^{1,2, *}$, Elizabeth Álvarez², Jairo Castaño-Zapata ${ }^{1}$ \\ ${ }^{1}$ Facultad de Ciencias Agropecuarias. Universidad de Caldas, Manizales, Colombia. \\ ${ }^{2}$ Centro Internacional de Agricultura Tropical (CIAT), Cali, Colombia.
}

\begin{abstract}
Resumen
La antracnosis es una de las enfermedades que más afecta la producción de frutales tropicales en el mundo. El objetivo del presente trabajo fue identificar a nivel de especie aislamientos de Colletotrichum spp. causantes de la antracnosis en frutos de aguacate, banano, mango y tomate de árbol mediante el análisis filogenético multilocus empleando datos de las secuencias de la región espaciadora interna transcrita (ITS), y de los genes $\beta$-tubulina-2 y gliceraldehído-3-fosfato deshidrogenasa. Para cada especie se evaluaron características morfológicas de la colonia, los conidios y los apresorios. Se obtuvieron 16 aislamientos a partir de frutos con síntomas de antracnosis, los cuales se confirmaron como causantes de la enfermedad en frutos de sus respectivos hospedantes con el método de inoculación por herida y goteo. Se identificaron los aislamientos como Colletotrichum asianum, Colletotrichum fructicola, Colletotrichum musae dentro del complejo de especies de Colletotrichum gloeosporioides, o como Colletotrichum tamarilloi dentro del complejo de especies de Colletotrichum acutatum. El presente estudio aporta al conocimiento de las especies causantes de la antracnosis en frutas tropicales en Colombia, lo cual facilitará el diseño de técnicas de diagnóstico y la selección de estrategias óptimas de manejo de la enfermedad.
\end{abstract}

Palabras clave: análisis filogenético multilocus, complejo de especies, diversidad genética, diagnóstico.

Genetic identification of Colletotrichum isolates causing anthracnose in fruits of avocado, banana, mango and tamarillo

\begin{abstract}
Anthracnose is a major disease affecting the production of tropical fruit trees on a global level. Our objective was to identify at the species level Colletotrichum isolates causing anthracnose in fruits of avocado, banana, mango, and tamarillo by multilocus phylogenetic analysis based on sequencing data from the ITS region and from the $\beta$ tubulin- 2 and glyceraldehyde-3-phosphate dehydrogenase genes. We evaluated the morphology of colonies, conidia, and appressoria for each species. We obtained 16 isolates from fruits exhibiting symptoms of anthracnose, which were confirmed using the wound and drip inoculation method as causing anthracnose in fruits of their respective hosts. The isolates were identified as Colletotrichum asianum, Colletotrichum fructicola, or Colletotrichum musae within the Colletotrichum gloeosporioides species complex, or as Colletotrichum tamarilloi within the Colletotrichum acutatum species complex. This study contributes to the knowledge of species causing anthracnose in tropical fruits in Colombia, which will facilitate the design of diagnosis techniques and the selection of better disease management strategies.
\end{abstract}

Key words: Multilocus phylogenetic analysis, species complex, genetic diversity, diagnosis.

\section{Introducción}

La fruticultura en Colombia es una de las actividades productivas con mayor potencial por su amplia expansión en el mercado internacional e importancia en la dieta alimenticia de la población mundial (Reyes, et al., 2006). Durante las últimas cinco décadas, el área sembrada en frutas en Colombia pasó de aproximadamente 435.500 ha en 1970 a 665.000 ha en el 2010 (FAOSTAT, 2014). Sin embargo, la producción frutícola en Colombia se ve limitada por problemas fitosanitarios que afectan los rendimientos productivos del cultivo en campo o causan importantes pérdidas después de la cosecha. Uno de estos problemas fitosanitarios es la antracnosis, causada por el hongo fitopatógeno Colletotrichum spp., el cual puede afectar diversos tejidos de las plantas, como tallos, hojas,

\footnotetext{
*Correspondencia:

Lederson Gañán, legabet@gmail.com

Recibido: 21 de enero de 2015

Aceptado: 17 de junio de 2015
} 
flores y frutos. El deterioro de los frutos después de la cosecha limita la calidad de la fruta para exportación, con daños que varían desde pérdidas ligeras en calidad, con la consecuente reducción del precio de venta, hasta la pérdida total de las frutas (Jeffries, et al., 1990; Hindorf, 2000). En la fresa (Fragaria $\times$ ananassa) y en el tomate de árbol (Solanum betaceum), Colletrotrichum spp. puede ocasionar graves epidemias de antracnosis que resultan en pérdidas superiores al 50 \% (Sreenivasaprasad \& Talhinhas, 2005; Hyde, et al., 2009).

Los estudios de identificación del agente causante de la antracnosis en los frutales en Colombia se han basado principalmente en el uso de caracteres morfológicos y el empleo de la técnica molecular de reacción en cadena de la polimerasa (PCR), con cebadores específicos para la especie derivados de la región espaciadora interna transcrita (ITS) del ADNr, o secuenciación y análisis de la región ITS, dando como resultado la identificación de tres especies: $C$. gloeosporioides, $C$. acutatum y C. boninense (Afanador-Kafuri, et al., 2003; Contreras, 2006; Arenas, et al., 2007; Rojas-Triviño, 2008; Saldarriaga, et al., 2008; Martínez, et al., 2009; Sanabria, et al., 2010; Afanador-Kafuri, 2011; Granados-Benavides, et al., 2011; Hoyos-Carvajal, et al., 2011; Martínez, et al., 2011; Calderón, et al., 2012; Rueda, et al., 2013). Sin embargo, estas tres especies se consideran actualmente como un grupo o complejo de especies cuyo límite genético se ha definido mediante análisis filogenético multilocus. Además, luego de la tipificación de C. gloeosporioides (Cannon, 2008) y de C. acutatum (Than, et al., 2008), en diversos estudios se ha demostrado que muchas especies previamente identificadas como C. gloeosporioides o C. acutatum difieren de sus especímenes tipo. Por ejemplo, Phoulivong, et al. (2010) determinaron que ninguno de los aislamientos de Colletotrichum asociados con la antracnosis de frutas tropicales en Tailandia correspondían a los especímenes tipo de C. gloeosporioides s. str. o de C. acutatum s. str. Además, en la publicación de Weir, et al. (2012) y Damm, et al. (2012a), se determinó la presencia de las especies $C$. asianum y C. tamarilloi asociadas a la antracnosis del mango y del tomate de árbol en Colombia, respectivamente, aunque no se presentaron pruebas de patogenicidad que los identificaran como agentes causantes de la enfermedad.

El objetivo del presente estudio fue identificar a nivel de especie aislamientos de Colletotrichum spp. causantes de la antracnosis en frutas de aguacate (Persea americana), banano (Musa spp.), mango (Mangifera indica) y tomate de árbol ( $S$. betaceum) en Colombia mediante la caracterización morfológica y una filogenia sólidamente establecida mediante análisis filogenético multilocus.

\section{Materiales y métodos}

\section{Fuente de los aislamientos}

Los aislamientos de Colletotrichum spp. usados en el presente estudio se aislaron a partir de tejidos de frutos de banano, mango y tomate de árbol con síntomas de antracnosis y se obtuvieron como cultivos monoespóricos empleando la metodología descrita por Than, et al. (2008).

\section{Pruebas de patogenicidad}

La patogenicidad de los aislamientos obtenidos se verificó en frutos del hospedante del cual habían sido aislados. Los frutos se obtuvieron en estado de madurez fisiológica, no fueron tratados, y se lavaron con un flujo constante de agua destilada durante diez minutos, seguido por una esterilización de la superficie mediante inmersión en etanol (tres minutos), hipoclorito de sodio al $1 \%$ (cinco minutos), y agua destilada estéril (tres veces durante dos minutos cada vez), y se secaron al aire en cámara de flujo laminar sobre toalla de papel estéril. Los frutos se inocularon mediante el método de inoculación por herida y goteo depositando 6 $\mu \mathrm{L}$ de la suspensión conidial $\left(\sim 1 \times 10^{6}\right.$ esporas. $\left.\mathrm{mL}^{-1}\right)$ sobre el área de la herida previamente demarcada (Than, et al., 2008). Como control, se inoculó agua destilada estéril. Los frutos inoculados se colocaron en cámaras húmedas en condiciones estériles (humedad relativa cercana al $95 \%$ ) (Montri, et al., 2009), a temperatura ambiente $\left(24^{\circ} \mathrm{C}\right)$, y sometidos a regímenes normales de luz durante siete días (Than, et al., 2008). Por cada interacción entre aislamiento y hospedante se emplearon tres repeticiones y dos frutas como unidad experimental. Siete días después de la inoculación se evaluaron los síntomas de la enfermedad y se tomaron fragmentos del borde de las lesiones o del área inoculada (en caso de no observar síntomas). El organismo aislado se cultivó en agar de papa y dextrosa (PDA) y los caracteres de la colonia y su morfología se compararon con el cultivo inicialmente inoculado.

\section{Extracción de ADN genómico}

El ADN se extrajo a partir del micelio del hongo obtenido de cultivos puros en medio PDA (Difco Laboratories, Detroit, MI, USA), siguiendo el protocolo de extracción de ADN descrito por Damm, et al. (2008).

\section{Identificación de especies basada en análisis filogenético multilocus}

La región ITS completa del ADNr, así como las secuencias parciales de los genes TUB2 y GAPDH se amplificaron mediante PCR y posteriormente se secuenciaron usando los pares de cebadores ITS-5 + ITS-4 (White, et al., 1990), Bt2a + Bt2b (Glass \& Donaldson, 1995) y GDF1 + GDR1 (Guerber, et al., 2003), respectivamente.

Las amplificaciones de PCR se llevaron a cabo en un volumen de reacción final de $25 \mu \mathrm{L}$ consistente en $10 \mathrm{ng}$ de ADN, una concentración final $1 \mathrm{X}$ del tampón DreamTaq Green PCR Master Mix (Thermo Fisher Scientific Inc.), $0,5 \mu \mathrm{M}$ de cada cebador y agua esterilizada para cromatografía líquida de alta eficacia (high performance liquid chromatography, HPLC). Para el proceso de amplificación se usó un termociclador PTC-100 (MJ Research, Watertown, 
MA, USA), con los programas térmicos de amplificación descritos por Prihastuti, et al. (2009). Los productos de PCR se enviaron al laboratorio de la unidad de biotecnología de la Iowa State University, USA, para la secuenciación en ambas direcciones con un secuenciador de ADN Applied Biosystems 3730xl (Applied Biosystems, Inc., Foster City, CA, USA). Las secuencias derivadas de este estudio se depositaron en la base de datos GenBank ${ }^{\circledR}$ (Tabla 1).

Para los análisis filogenéticos, las secuencias de los aislamientos de Colletotrichum obtenidos en el presente estudio se compararon con las de especímenes del tipo de Colletotrichum obtenidas en la base de datos GenBank ${ }^{\circledR}$. Para cada gen se hicieron alineamientos individuales y, posteriormente, los tres genes se concatenaron usando el programa FASconCAT v.1.0 (Kück \& Meusemann, 2010). Para cada gen se crearon particiones separadas y para cada una de estas se determinó el modelo de sustitución de nucleótidos que mejor se ajustara mediante el programa jModelTest 0.1.1 (Posada, 2008), y de acuerdo al criterio de información Akaike corregido (AICc). La reconstrucción filogenética se hizo mediante inferencia bayesiana, usando el programa MrBayes v. 3.2.1 (Ronquist, et al., 2012). El análisis mediante el método de Montecarlo basado en las cadenas de Markov (Markov chain Montecarlo method, MCMC) se aplicó al conjunto de datos con los modelos de sustitución determinados separadamente para cada partición. Para el análisis bayesiano, se corrieron cuatro cadenas de MCMC dos veces por $1 \times 10^{7}$ generaciones, con un muestreo de árboles cada 1.000 generaciones. Después se

Tabla 1. Números de acceso en GenBank ${ }^{\circledR}$ de los aislamientos de Colletotrichum spp. identificados en el presente estudio

\begin{tabular}{|c|c|c|c|c|}
\hline \multirow[t]{2}{*}{ Especie } & \multirow[t]{2}{*}{ Aislamiento } & \multicolumn{3}{|c|}{ Números de acceso en GenBank ${ }^{\circledR}$} \\
\hline & & ITS & GAPDH & TUB2 \\
\hline \multirow[t]{5}{*}{ C. asianum } & MnM1 & KM233236 & KM233220 & KM233252 \\
\hline & MnM2 & KM233237 & KM233221 & KM233253 \\
\hline & MnM3 & KM233238 & KM233222 & KM233254 \\
\hline & MnM4 & KM233239 & KM233223 & KM233255 \\
\hline & MnM5 & KM233240 & KM233224 & KM233256 \\
\hline \multirow[t]{2}{*}{ C. fructicola } & AM1 & KM233229 & KM233213 & KM233245 \\
\hline & AM2 & KM233230 & KM233214 & KM233246 \\
\hline \multirow[t]{5}{*}{ C. musae } & BM1 & KM233231 & KM233215 & KM233247 \\
\hline & BM2 & KM233232 & KM233216 & KM233248 \\
\hline & BM3 & KM233233 & KM233217 & KM233249 \\
\hline & BM4 & KM233234 & KM233218 & KM233250 \\
\hline & BM5 & KM233235 & KM233219 & KM233251 \\
\hline \multirow[t]{4}{*}{ C. tamarilloi } & TM1 & KM233241 & KM233225 & KM233257 \\
\hline & TM2 & KM233242 & KM233226 & KM233258 \\
\hline & TM3 & KM233243 & KM233227 & KM233259 \\
\hline & TM4 & KM233244 & KM233228 & KM233260 \\
\hline
\end{tabular}

omitió el primer $25 \%$ de los árboles generados (burn-in) y los árboles restantes de la muestra se usaron para estimar un árbol de consenso con un límite de probabilidades posteriores de $50 \%$.

\section{Caracterización morfológica}

Para los estudios morfológicos, se depositaron $6 \mu \mathrm{L}$ de una suspensión de conidios $\left(\sim 1 \times 10^{6}\right.$ conidios. $\left.\mathrm{mL}^{-1}\right)$ sobre el centro de una caja de Petri de 9,5 cm de diámetro con medio de cultivo Difco PDA (39 g. $\mathrm{L}^{-1}$ ) y antibiótico (tetraciclina: $\left.50 \mathrm{mg} . \mathrm{L}^{-1}\right)$. Los cultivos se incubaron a $20 \pm 1^{\circ} \mathrm{C}$ durante 12 horas de luz y 12 horas de oscuridad y a los 10 días de crecimiento se registró su apariencia y su diámetro (Than, et al., 2008). Se empleó un diseño completamente al azar, con tres réplicas por aislamiento.

Para la producción de conidios, los aislamientos se sembraron en medio de cultivo PDA (39 g.L ${ }^{-1}$ ) tratado con fragmentos de papel de filtro esterilizado en autoclave.

En la producción de apresorios se empleó la técnica de cultivo en portaobjetos (Cai, et al., 2009), para lo cual se tomaron cortes del cultivo en medio PDA (39 g. $\mathrm{L}^{-1}$ ) de $10 \mathrm{~mm}^{2}$ y se colocaron sobre un portaobjetos. Luego se depositaron 30 $\mu \mathrm{L}$ de una suspensión conidial $\left(1 \times 10^{6}\right.$ conidios. $\left.\mu \mathrm{L}^{-1}\right)$ sobre los bordes del corte y se cubrió con placas cubreobjetos (Johnston \& Jones, 1997). Los cultivos se incubaron durante 5 a 7 días a temperatura ambiente $\left(24^{\circ} \mathrm{C}\right)$ y bajo condiciones de gran humedad en cajas plásticas con tapa (Chaky, et al., 2001).

Se registró la forma, la longitud y el ancho de cada aislamiento de 30 conidios o apresorios. Las observaciones y mediciones microscópicas se hicieron bajo un microscopio Leica (Type 020-519-503-LB30T) con un aumento de 1.000X. Las estructuras en cada placa se fotografiaron con cámara digital (Canon Powershot ELPH 500 HS) adaptada al lente del microscopio y las imágenes se usaron para medir la longitud y el ancho de los conidios y apresorios empleando el programa ImageJ (Ferreira \& Rasband, 2012).

Los promedios y la desviación estándar de la media se estimaron para cada variable por especie con el programa SAS, versión 9.2 (SAS, 2008).

\section{Resultados}

Se obtuvieron 16 cultivos monoespóricos de Colletotrichum spp., los cuales causaron síntomas típicos de antracnosis en los frutos inoculados del hospedante que habían sido aislados. Tomando en cuenta los síntomas, se aisló nuevamente el patógeno y sus características morfológicas resultaron similares al originalmente inoculado, con lo que se cumplieron los postulados de Koch.

\section{Análisis filogenético}

La información combinada de las secuencias parciales de los genes GAPDH y TUB2 y de la región ITS completa del ADNr correspondiente a los aislamientos de Colletorichum 
spp. obtenidos en el presente estudio y a las especies de referencia (obtenidas en el Genbank ${ }^{\circledR}$ ), comprendió 1.240 nucleótidos (incluidos los huecos). Los límites de cada gen y los modelos de sustitución de los nucleótidos usados en el análisis filogenético fueron los siguientes: ITS: 1-554 (HKY+G), GAPDH: 555-821 (K80+G), TUB2: 822-1240 (K80+G).

De acuerdo al análisis filogenético los aislamientos se distribuyeron entre los complejos C. gloeosporioides s. lat. y C. acutatum s. lat. (Figura 1). Los cinco aislamientos de mango que se obtuvieron (MnM1, MnM2, MnM3, MnM4 y MnM5), se agruparon con las cepas de referencia de la especie C. asianum; los cinco aislamientos de banano (BM1, BM2, BM3, BM4 y BM5), se agruparon con las cepas de referencia de la especie $C$. musae, en tanto que los cuatro aislamientos de tomate de árbol (TM1, TM2, TM3, $\mathrm{TM} 4)$, se ubicaron en un subclado bien soportado $(\mathrm{PP}=1)$, correspondiente a la especie $C$. tamarilloi.

\section{Estudios morfológicos}

Las características morfológicas se detallaron para cada especie en las anotaciones taxonómicas. Los promedios para las variables mencionadas fueron similares a aquellos descritos en la literatura científica (Prihastuti, et al., 2009; Weir, et al., 2012; Damm, et al., 2012a; Lima, et al., 2013).

\section{Anotaciones taxonómicas}

Colletotrichum asianum Prihastuti, L. Cai \& K.D. Hyde, Fungal Diversity 39: 96. 2009.

Especímenes examinados: MnM1 y MnM2; fuente: frutos de mango ( $M$. indica) cv Tommy con síntomas de antracnosis, obtenidos en plazas de mercado de Quinchía (Risaralda); recolector: L. Gañán, mayo de 2013. MnM3, MnM4, MnM5; frutos de mango ( $M$. indica) cv Tommy con síntomas de antracnosis, obtenidos en plaza de mercado de Medellín (Antioquia); recolector: L. Afanador-Kafuri, junio de 2013.

Descripción: colonias sobre medio PDA, redondas a irregulares, de borde entero a semiondulado, ralas a elevadas, de 62 a $75 \mathrm{~mm}$ de diámetro $(\overline{\mathrm{X}}=68,7 \pm 4,2)$ en 10 días a $20^{\circ} \mathrm{C}$. Micelio aéreo denso, algodonoso, de color blanco a blanco grisáceo y gris. Setas raramente observadas. Conidios de 13,3-20,1

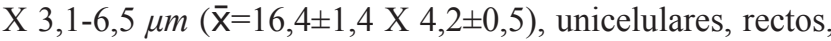
cilíndricos con extremos oblongos a ligeramente redondeados. Apresorios de 6,3-15,0 X 3,0-8,4 $\mu \mathrm{m}(\overline{\mathrm{X}}=12,6 \pm 2,0$ X 5,9 $\pm 1,5)$, simples, globosos a fusoides y algunas veces irregulares con uno a tres lóbulos amplios y poco profundos.

Notas: de acuerdo con Weir, et al. (2012), esta especie frecuentemente se aísla de mango (M. indica). La especie $C$. asianum fue descrita por primera vez en Tailandia en frutos de café (Coffea arabica) (Prihastuti, et al., 2009), y se ha reportado en otros países como Australia, Japón, Filipinas, India, Tailandia, Sri Lanka, Brasil, Colombia y Panamá (Weir, et al., 2012; Lima, et al., 2013; Krishnapillai \& WilsonWijeratnam, 2014). Sin embargo, aunque el patógeno se ha reportado asociado con $M$. indica en Colombia (Weir, et al., 2012), en el presente estudio se comprobó la patogenicidad de la especie en frutos del mismo hospedante. Los síntomas en los frutos inoculados se presentaron inicialmente como una decoloración del tejido y posteriormente con necrosis, la cual fue alargándose en el área con el tiempo y presentando síntomas típicos como los observados en el campo, es decir, lesiones ovales de color café oscuro a negro en la superficie del fruto que se extienden hasta coalescer con otras lesiones y cubrir la totalidad del fruto (Arauz, 2000). Además, el interior de los frutos inoculados se vio afectado hasta su pudrición. El patógeno se aisló de nuevo a partir de los frutos afectados y la morfología fue similar a la del aislamiento originalmente inoculado, cumpliendo así con los postulados de Koch.

Colletotrichum fructicola Prihastuti, L. Cai \& K.D. Hyde, Fungal Diversity 39:158. 2009.

Especímenes examinados: AM1, AM2; fuente: frutos de aguacate (P. americana) con síntomas de antracnosis, obtenidos en plaza de mercado de Medellín (Antioquia); recolector: L. Afanador-Kafuri, junio de 2013.

Descripción: colonias en medio PDA, redondas, de borde entero, elevadas, de 78 a $90 \mathrm{~mm}$ de diámetro $(\overline{\mathrm{X}}=84 \pm 6)$ después de 10 días a $20^{\circ} \mathrm{C}$. Micelio algodonoso de color blanco a verde oliváceo. Setas, no se observaron (Figura 2A). Conidios de 10,3-20,0 X 2,0-4,8 $\mu \mathrm{m}(\overline{\mathrm{X}}=13,6 \pm 1,7 \mathrm{X}$ $3,7 \pm 0,5)$, unicelulares, rectos, cilíndricos, con extremos redondos a oblongos (Figura 2B). Apresorios de 8,6-16,8 $\mathrm{X} 4,7-7,0 \mu \mathrm{m}(\overline{\mathrm{X}}=12,0 \pm 3,1 \times 5,8 \pm 0,7)$, simples (fusoides) o irregulares con uno a tres lóbulos amplios y poco profundos a profundos (Figura 2C).

Notas: la especie $C$. fructicola fue descrita por primera vez en Tailandia (Prihastuti et al., 2009), y se ha reportado en otros países de Asia, África, Europa y América en diversos hospedantes vegetales (Weir, et al., 2012; Phoulivong, et al., 2012; Sharma \& Shenoy, 2013; Jiang, et al., 2014). En Colombia, C. fructicola se ha reportado como causante de antracnosis en tallos de mora (Rubus glaucus B.) del ecotipo Castilla (Afanador-Kafuri, et al., 2014). Al igual que en el presente estudio, en Australia el patógeno se aisló a partir de frutos de aguacate con síntomas de pudrición (Weir, et al., 2012). Sin embargo, este es el primer reporte que lo confirma como patógeno en aguacates cv. Hass en Colombia, en los cuales causó síntomas de pudrición y una excesiva esporulación sobre las áreas afectadas (Figura 2D).

Colletotrichum musae (Berk. \& M.A. Curtis) Arx, Verh. Kon. Ned. Akad. Wetensch., Afd. Natuurk., Sect. 2 51(3): 107. 1957.

Especímenes examinados: BM1, BM2, BM3, BM4, BM5; fuente: frutos de banano (Musa AAA) con síntomas de pudrición, obtenidos en plaza de mercado de Quinchía (Risaralda) y Palmira (Valle del Cauca); recolector: L. Gañán, mayo de 2013. 


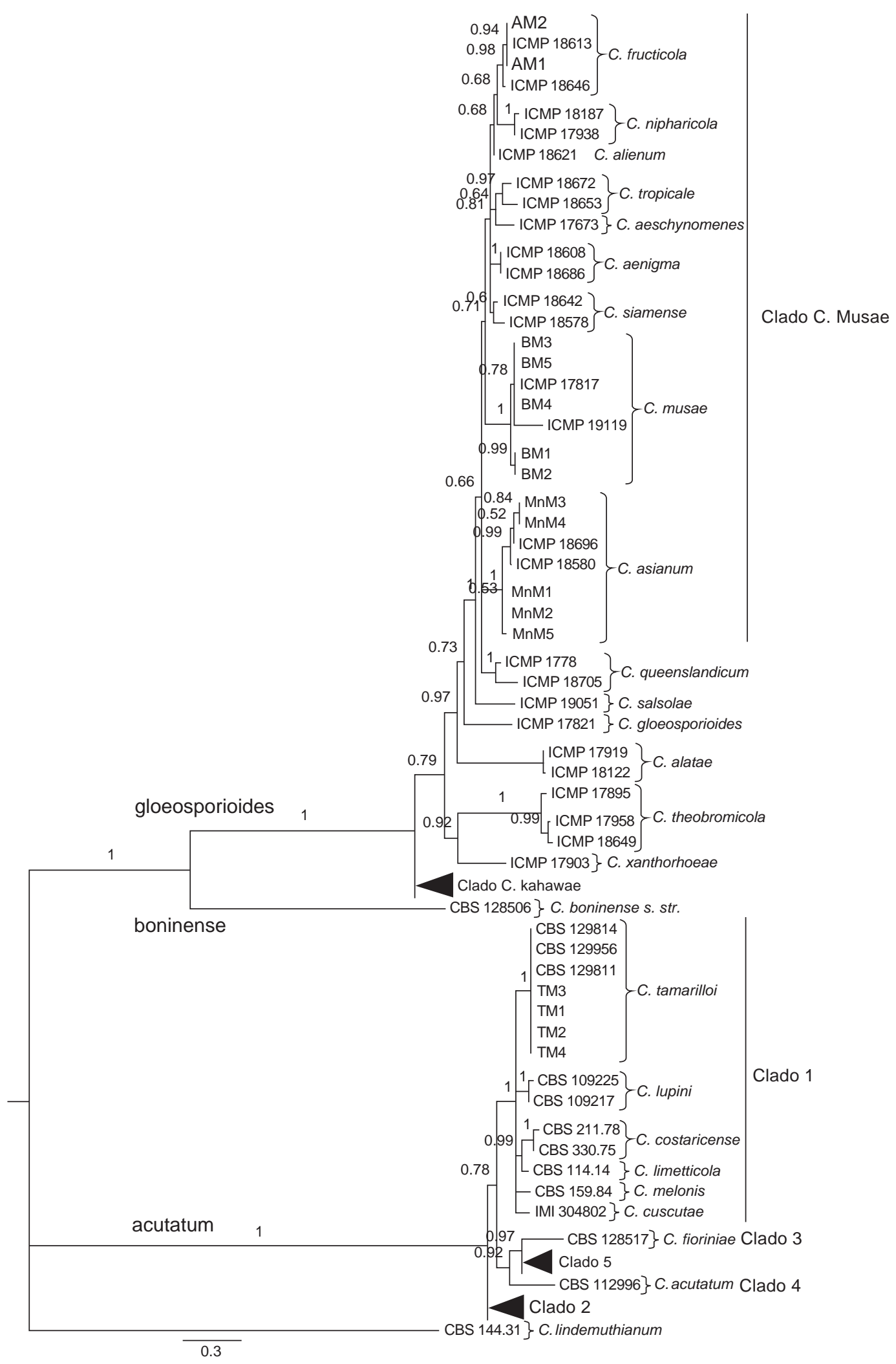

Figura 1. Arbol filogenético de consenso basado en inferencia bayesiana que ilustra la relación de los aislamientos de Colletotrichum asociados con la antracnosis en frutos de mango, banano, tomate de árbol y aguacate dentro de los complejos de especies C. gloeosporioides y C. acutatum en Colombia. El árbol se generó mediante secuencias combinadas de la región ITS, y de los genes GAPDH y TUB2, cada uno con un modelo separado de evolución de ADN. C. lindemuthianum (CBS 144.31) se usó como grupo externo. Los números en los nodos corresponden a las probabilidades posteriores. 
Descripción: colonias en medio PDA, redondas a irregulares, de borde entero a semiondulado, elevadas, de 68 a $90 \mathrm{~mm}$ de diámetro $(\overline{\mathrm{X}}=82,7 \pm 9,1)$ después de 10 días a $20^{\circ} \mathrm{C}$. Micelio aéreo esparcido, semialgodonoso a ralo y de color blanco a crema y café oliváceo. Conidios de 10,8-18,5 X 3-5,9 $\mu \mathrm{m}(\overline{\mathrm{X}}=13,0 \pm 1,4 \times \mathrm{X} 4,1 \pm 0,5)$, unicelulares, rectos, elípticos o cilíndricos, con extremos redondos a oblongos, algunas

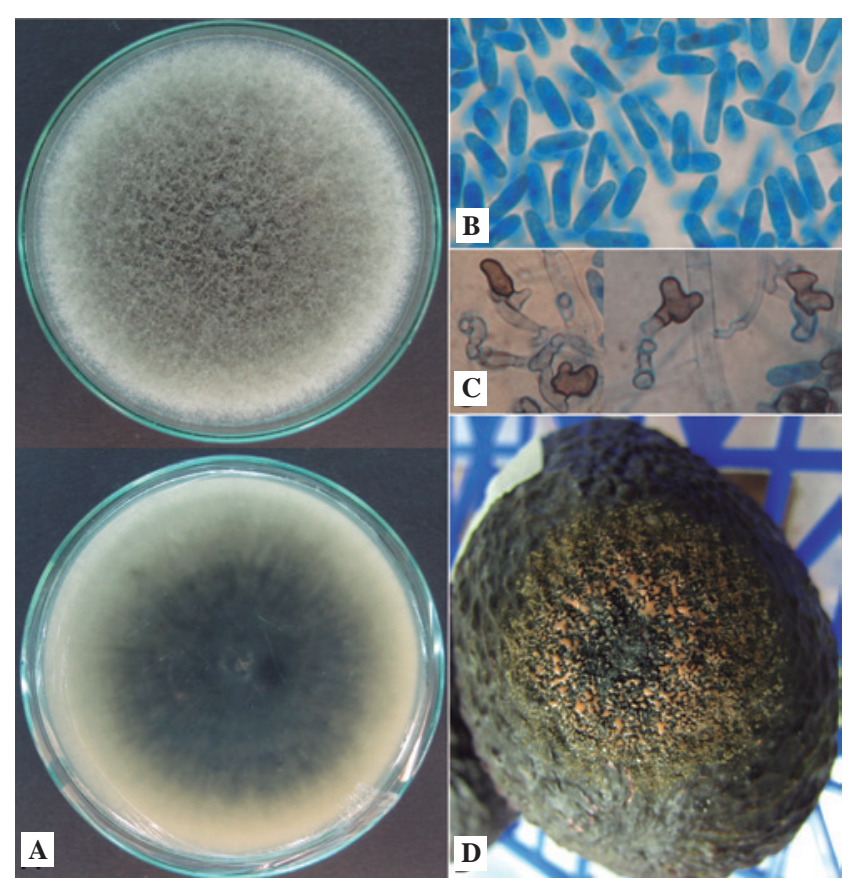

Figura 2. Colletotrichum fructicola: A. Colonia después de 10 días de crecimiento en medio PDA a $20^{\circ} \mathrm{C}$ (aislamiento AM1); B. Conidios; C. Apresorios; D. Síntomas y esporulación en un fruto de aguacate cv. Hass inoculado artificialmente con suspensión de esporas del aislamiento AM1

Descripción: colonias en medio PDA, redondas, de borde entero, elevadas, de 78 a $90 \mathrm{~mm}$ de diámetro $(\overline{\mathrm{X}}=84 \pm 6)$ después de 10 días a $20^{\circ} \mathrm{C}$. Micelio algodonoso de color blanco a verde oliváceo. Setas, no se observaron (Figura 2A). Conidios de 10,3-20,0 X 2,0$4,8 \mu \mathrm{m}(\bar{X}=13,6 \pm 1,7 \times 3,7 \pm 0,5)$, unicelulares, rectos, cilíndricos, con extremos redondos a oblongos (Figura 2B). Apresorios de 8,6-16,8 X 4,7-7,0 $\mu \mathrm{m}$ ( $\overline{\mathrm{X}}=12,0 \pm 3,1 \mathrm{X} 5,8 \pm 0,7$ ), simples (fusoides) o irregulares con uno a tres lóbulos amplios y poco profundos a profundos (Figura 2C).

Notas: la especie $C$. fructicola fue descrita por primera vez en Tailandia (Prihastuti et al., 2009), y se ha reportado en otros países de Asia, África, Europa y América en diversos hospedantes vegetales (Weir, et al., 2012; Phoulivong, et al., 2012; Sharma \& Shenoy, 2013; Jiang, et al., 2014). En Colombia, C. fructicola se ha reportado como causante de antracnosis en tallos de mora (Rubus glaucus B.) del ecotipo Castilla (Afanador-Kafuri, et al., 2014). Al igual que en el presente estudio, en Australia el patógeno se aisló a partir de frutos de aguacate con síntomas de pudrición (Weir, et al., 2012). Sin embargo, este es el primer reporte que lo confirma como patógeno en aguacates cv. Hass en Colombia, en los cuales causó síntomas de pudrición y una excesiva esporulación sobre las áreas afectadas (Figura 2D). veces con ligera disminución hacia la base. Apresorios de 8,0-23,8 X 3,7-11,7 $\mu \mathrm{m}(\overline{\mathrm{X}}=12,7 \pm 3,7 \times 6,1 \pm 1,7)$, simples (fusoides) a irregulares, con lóbulos amplios y profundos.

Notas: C. musae es la principal especie asociada con la antracnosis o pudrición de frutos de banano (Musa spp.). Al igual que en los estudios de Weir, et al. (2012) y Su, et al. (2011), en este estudio no se observó la presencia de un estado perfecto o Glomerella, conocido como G. musae (Rodríguez \& Owen, 1992; Krauss, et al., 2001), el cual nunca se ha publicado de forma válida. El presente reporte se correspondió válidamente con el primero según los estudios morfológicos, de patogenicidad y genéticos, confirmando a C. musae como agente causante de la antracnosis del banano en Colombia. Los síntomas se observaron dos días después de la inoculación de los frutos de banano con conidios de C.musae como lesiones café oscuras a negras que se fueron ampliando con el tiempo, causando depresión del tejido afectado; posteriormente se observó la presencia de acérvulos alrededor de las depresiones en la superficie.

Colletotrichum tamarilloi Damm, P.F. Cannon \& Crous, Studies in Micology. 73:105. 2012.

Especímenes examinados: TM1, TM2, TM3 у TM4; fuente: frutos de tomate de árbol (S. betaceum) con síntomas de antracnosis, obtenidos en plaza de mercado de Quinchía (Risaralda); recolector: L. Gañán, 2013.

Descripción: colonias en medio PDA, irregulares, de borde semiondulado, elevadas, de 47 a $60 \mathrm{~mm}$ de diámetro $(\overline{\mathrm{x}}=55,7$ $\pm 4,7)$ después de 10 días a $20{ }^{\circ} \mathrm{C}$. Micelio algodonoso de color blanco a blanco grisáceo o café oliváceo. Setas, no se observaron. Conidios de 9,7-16,9 X 2,2-6,1 $\mu$ m ( $\bar{x}=13,2 \pm 1,4$ $X 3,6 \pm 0,6)$, unicelulares, rectos, cilíndricos a fusiformes, con uno o ambos extremos agudos. Apresorios de 5,9-12,3 X 3,4-6,1 $\mu m(\bar{X}=8,2 \pm 2,0$ X 4,6 $\pm 0,7$ ), simples (globosos a elípticos y fusoides), algunas veces irregulares, con uno a dos lóbulos poco profundos.

Notas: el nombre de la especie fue asignado por Damm, et al. (2012a) en referencia al nombre del hospedante (tamarillo, S. betaceum) del cual fue aislada, pero sin estudios de patogenicidad. En el presente estudio se encontró que los aislamientos obtenidos de frutos de tomate de árbol con síntomas de antracnosis causaron la enfermedad en nuevas inoculaciones en frutos del mismo hospedante. A partir de las nuevas inoculaciones se logró un nuevo aislamiento de individuos con características morfológicas similares al originalmente inoculado, cumpliendo así con los postulados de Koch para esta asociación. Esta especie se ha reportado únicamente en Colombia (Damm, et al., 2012a), aunque hasta la fecha se han reportado en la base de datos del GenBank ${ }^{\circledR}$ secuencias con los números de acceso KJ633118 y KJ633119 del gen GAPDH, provenientes de aislamientos asociados con antracnosis en giló (Solanum gilo) del Brasil, los cuales se identificaron como C. tamarilloi (NCBI, 2014). Además, el primer autor del presente artículo identificó 
como C. tamarilloi el aislamiento LM06 de la colección del Centro Internacional de Agricultura Tropical (CIAT) recolectado en el 2007 en Ríonegro (Antioquia) a partir de frutos de lulo (Solanum quitoense) con síntomas de antracnosis. La patogenicidad del aislamiento se evaluó en estudios previos en el laboratorio de patología de la yuca del CIAT, y se lo consideró como muy patógenico en frutos de lulo de la variedad Castilla empleando el método de inoculación por herida y disco de agar con micelio (informe del laboratorio de patología de la yuca, sin publicar). Se ha reportado la asociación de $C$. gloeosporioides s. lat. con la antracnosis en S. betaceum (Calderón, et al., 2012), sin embargo, en el presente estudio no se obtuvieron aislamientos de este complejo que afectaran el tomate de árbol.

\section{Discusión}

El análisis filogenético multilocus empleado en el presente estudio es actualmente el enfoque usado para la identificación y descripción de las especies del género Colletotrichum (Damm, et al., 2012a, 2012b; Weir, et al., 2012; Cannon, et al., 2012; Lima, et al., 2013; Udayanga, et al., 2013; Huang, et al., 2013; Liu, et al., 2013). La preferencia de este análisis se debió a que no se alcanzó resolución taxonómica con base en las características morfológicas y el uso de genes o regiones poco informativas a nivel individual (por ejemplo, la región ITS del ADNr) (Crouch, et al., 2009), especialmente en el caso de muchas de las especies y clados de los complejos C. acutatum y C. gloeosporioides. Por ejemplo, las secuencias de la región ITS del ADNr no pueden diferenciar aislamientos de la especie C. tropicale de aislamientos de la especie $C$. siamense, como tampoco entre las especies $C$. fructicola y Colletotrichum aeschynomenes (Weir, et al., 2012). Por lo tanto, un sistema de identificación eficaz debe contemplar el uso de la región ITS, así como de genes alternativos conservados pero variables (Cannon, et al., 2012; Damm, et al., 2012a, 2012b). Por ejemplo, en el complejo acutatum los dos genes de identificación más importantes son el TUB2 y el GAPDH (Damm, et al., 2012a). En el presente estudio este enfoque permitió la delimitación confiable a nivel de complejos de especies, así como de clados y de especies, de los aislamientos de Colletotrichum obtenidos. De acuerdo con el análisis, se identificaron las especies C. asianum, C. tamarilloi, C. musae y C. fructicola, las cuales se obtuvieron de frutos de mango, tomate de árbol, banano y aguacate, respectivamente, con síntomas típicos de antracnosis, determinándose su asociación como causante de la enfermedad en las pruebas de patogenicidad.

En cuanto a la relación de especificidad con el hospedante, solo $C$. musae tiene una relación específica con especies vegetales del género Musa, así como una amplia dispersión geográfica (Su, et al., 2011; Weir, et al., 2012). De igual manera, C. tamarilloi se ha reportado únicamente en hospedantes del género Solanum (Damm, et al., 2012a; NCBI, 2014; informe del laboratorio de patología de la yuca del CIAT, sin publicar).
C. fructicola ha sido reportada por Afanador-Kafuri, et al. (2014) como causante de antracnosis en mora del ecotipo Castilla, y en el presente estudio se la reporta como causante de antracnosis en frutos de aguacate cv. Hass, lo que indica que en campo podría presentarse la infección cruzada, puesto que los dos cultivos pueden estar sembrados en zonas cercanas.

La identificación de las especies de Colletotrichum en el presente trabajo aporta al conocimiento de la etiología de la antracnosis en frutas tropicales de Colombia, lo cual es importante para el desarrollo y el mejoramiento de las técnicas de diagnóstico de las especies de interés y un elemento clave en la selección de prácticas de manejo integral de la enfermedad.

\section{Agradecimientos}

A la Doctora Lucía Afanador-Kafuri, por proporcionar algunos de los aislamientos identificados en el presente estudio.

\section{Conflicto de intereses}

Los autores declaran que no tienen conflicto de intereses.

\section{Bibliografía}

Afanador-Kafuri, L. 2011. Antracnosis de la mora de castilla (Rubus glaucus Benth): variabilidad del agente causante e identificación de fuentes de resistencia en germoplasma de Rubus spp. en Colombia. Tesis. Universidad Nacional de Colombia. Medellín, Colombia.

Afanador-Kafuri, L., González, A., Gañán, L., Mejía, J.F., Cardona, N., Álvarez, E. 2014. Characterization of the Colletotrichum species causing anthracnose in Andean blackberry in Colombia. Plant Disease. 98 (11): 1503-1513.

Afanador-Kafuri, L., Minz, D., Maymon, M., Freeman, S. 2003. Characterization of Colletotrichum gloeosporioides isolates from Tamarillo, Passiflora and Mango in Colombia and identification of unique species from the genus. Phytopathology. 93: 579-587.

Arauz, L. F. 2000. Mango anthracnose: Economic impact and current options for integrated management. Plant Disease. 84 (6): 600-611.

Arenas, A., Álvarez, E., Afanador-Kafuri, L., Mejía, J. F., González, A. 2007. Especies de Colletotrichum asociadas con la antracnosis de la mora de Castilla (Rubus glaucus Benth) en el Valle del Cauca. Fitopatología Colombiana. 31 (1): 7-14.

Cai, L., Hyde, K. D., Taylor, P. W. J., Weir, B. S., Waller, J., Abang, M. M., Zhang, J. Z., Yang, Y. L., Phoulivong, S., Liu, Z. Y., Prihastuti, H., Shivas, R. G., McKenzie, E. H. C., Johnston, P. R. 2009. A polyphasic approach for studying Colletotrichum. Fungal Diversity. 39: 183-204.

Calderón, C., Cárdenas, M., Restrepo, S., Jiménez, P. 2012. Morphological characterization of Colletotrichum species isolated from mango and tree tomato in Cundinamarca and Tolima, Colombia. Phytopathology. 102: S4.18 
Cannon, P. F., Buddie, A. G., Bridge, P. D. 2008. The typification of Colletotrichum gloeosporioides. Mycotaxon. 104: 189-204.

Cannon, P. F., Damm, U., Johnston, P. R., Weir, B. S. 2012. Colletotrichum - current status and future directions. Studies in Mycology. 73 (1): 181-213.

Chaky, J., Anderson, K., Moss, M., Vaillancourt, L. 2001. Surface hydrophobicity and surface rigidity induce spore germination in Colletotrichum graminicola. Phytopathology. 91 (6): 558-564.

Contreras, C. A. 2006. Caracterización y pruebas de patogenicidad cruzada entre aislamientos de Colletotrichum spp. obtenidos de frutos de lulo (Solanum quitoense Lam), tomate de árbol (Solanum betaceum Sendt), granadilla (Passiflora ligularis Juss), mango (Mangifera indica L.) y tallos de mora (Rubus glaucus Benth) con síntomas de antracnosis. Trabajo de grado. Facultad de Ciencias Básicas. Pontificia Universidad Javeriana. Bogotá. p. 115.

Damm, U., Cannon, P. F., Woudenberg, J. H. C., Crous, P. W. 2012a. The Colletotrichum acutatum species complex. Studies in Mycology. 73 (1): 37-113.

Damm, U., Cannon, P. F., Woudenberg, J. H. C., Johnston, P. R., Weir, B. S., Tan, Y. P., Shivas R. G., Crous, P. W. 2012b. The Colletotrichum boninense species complex. Studies in Mycology. 73 (1): 1-36.

Damm, U., Mostert, L., Crous, P. W. \& Fourie, P. H. 2008. Novel Phaeoacremonium species associated with necrotic wood of Prunus trees. Persoonia. 20: 87-102.

FAOSTAT. 2014. Food and Agriculture Organization statistical database. Fecha de consulta: 12 de abril de 2014. Disponible en: http://faostat.fao.org/.

Ferreira, T. \& Rasband, W. 2012. ImageJ User Guide/IJ 1.46r. Bioimage Informatics. http://rsb.info.nih.gov/ij/docs/guide/ user-guide.pdf

Glass, N. L. \& Donaldson, G. 1995. Development of primer sets designed for use with PCR to amplify conserved genes from filamentous ascomycetes. Applied and Environmental Microbiology. 61: 1323-1330.

Granados-Benavides, G. M., Guevara-Castro, Y. A., Montaña, J. S., Forero de la Rotta, M. C. 2011. Caracterización biológica y molecular de aislamientos de Colletotrichum procedentes de frutales de clima frío moderado. Fitopatología Colombiana. 35 (1) (Suplemento):34.

Guerber, J. C, Liu, B., Correll, J. C., Johnston, P. R. 2003. Characterization of diversity in Colletotrichum acutatum sensu lato by sequence analysis of two gene introns, mtDNA and intron RFLPs, and mating compatibility. Mycologia. 95: 872-895.

Hindorf, H. 2000. Colletotrichum species causing anthracnose of tropical crops. Plant Pathology. 39: 343-366.

Hoyos-Carvajal, L., Castillo, S., Benítez, S., Ortiz, E., Farfán, L., Riascos, D. 2011. Plant diseases in exotic purple passion fruit in the Andean zone. Journal of Plant Pathology. 93 (4) (Supplement):35.
Huang, F., Chen, G. Q., Hou, X., Fu, Y. S., Cai, L., Hyde, K. D., Li H. Y. 2013. Colletotrichum species associated with cultivated citrus in China. Fungal Diversity. 61 (1): 61-74.

Hyde, K. D., Cai, L., McKenzie, E.H.C., Yang, Y.L., Zhang. J.Z., Prihastuti, H. 2009. Colletotrichum: A catalogue of confusion. Fungal Diversity. 39: 1-17.

Jeffries, P, Dodd, J. C., Jeger, M. J. \& Plumbley, R. A. 1990. The biology and control of Colletotrichum species on tropical fruits crops. Plant Pathology. 39: 343-366.

Jiang, J., Zhai, H., Li, H., Wang, Z., Chen, Y., Hong, N., Wang, G., Chofong, G. N., Xu, W. 2014. Identification and characterization of Colletotrichum fructicola causing black spots on young fruits related to bitter rot of pear (Pyrus bretschneideri Rehd.) in China. Crop Protection. 58: 41-48.

Johnston, P. R. \& Jones, D. 1997. Relationships among Colletotrichum isolates from fruit rots assessed using rDNA sequences. Mycologia. 89: 420-430.

Krauss, U., Matthews, P., Bidwell, R., Hocart, M., Anthony, F. 2001. Strain discrimination by fungal antagonists of Colletotrichum musae: Implications for biocontrol of crown rot of banana. Mycological Research. 105: 67-76.

Krishnapillai, N. \& Wilson Wijeratnam, R. S. 2014. First Report of Colletotrichum asianum causing anthracnose on Willard mangoes in Sri Lanka. New Disease Reports. 29:1. http:// dx.doi.org/10.5197/j.2044-0588.2014.029.001

Kück, P. \& Meusemann, K. 2010. FASconCAT: Convenient handling of data matrices. Molecular Phylogenetics and Evolution. 56: 1115-1118.

Lima, N. B., Batista, M., DeMorais, M. A., Jr., Barbosa, M. A. G., Michereff, S. J., Hyde, K. D., Marcos, P. S. 2013. Five Colletotrichum species are responsible for mango anthracnose in northeastern Brazil. Fungal Diversity. 61 (1): 75-88.

Liu, F., Damm, U., Cai, L., Crous, P. W. 2013. Species of the Colletotrichum gloeosporioides complex associated with anthracnose diseases of Proteaceae. Fungal Diversity. 61 (1): 89-105.

Martínez, A. P., Higuera, B. L., Martínez, S. T. 2011. Selección de un método de extracción para RNA proveniente del hongo Colletotrichum acutatum, agente causal de la antracnosis en lulo Solanum quitoense Lam. Fitopatología Colombiana. 35 (1) (Suplemento):9.

Martínez, E. P., Hio, J. C., Osorio, J. A., Torres, M. F. 2009. Identification of Colletotrichum species causing anthracnose on Tahiti lime, tree tomato and mango. Agronomía Colombiana. 27 (2): 211-218.

National Center for Biotechnology (NCBI). Colletotrichum tamarilloi isolate CJ6 GAPDH (GAPDH) gene, partial cds. Fecha de consulta: 20 de abril de 2014. Disponible en: http://www.ncbi.nlm.nih.gov/nuccore/KJ633118.1.

Phoulivong, S., McKenzie, E. H. C., Hyde, K. D. 2012. Cross infection of Colletotrichum species; a case study with tropical fruits. Current Research in Environmental \& Applied Mycology. 2 (2): 99-111. http://dx.doi.org/10.5943/ cream/2/2/2. 
Phoulivong, S., Cai, L., Chen, H., McKenzie, E. H. C., Abdelsalam, K., Chukeatirote, E., Hyde, K. D. 2010. Colletotrichum gloeosporioides is not a common pathogen on tropical fruits. Fungal Diversity. 44: 33-43.

Posada, D. 2008. jModelTest: Phylogenetic model averaging. Molecular Biology and Evolution. 25: 1253-1256.

Prihastuti, H., Cai, L., Chen, H., McKenzie, E. H. C., Hyde, K. D. 2009. Characterization of Colletotrichum species associated with coffee berries in northern Thailand. Fungal Diversity. 39: 89-109.

Reyes, R. M., Toro, J. M., Perfetti, J. J., Ruiz, D., Morales, J. R. 2006. Plan frutícola nacional. MADR, Ministerio de Agricultura y Desarrollo Rural. Documento técnico. Bogotá. 43 p.

Rodríguez, R. J. \& Owen, J. L. 1992. Isolation of Glomerella musae [teleomorph of Colletotrichum musae (Berk. \& Curt.) Arx] and segregation analysis of ascospore progeny. Experimental Mycology. 16: 291-301.

Rojas-Triviño, E. A. 2008. Identificación de estrategias de manejo de la antracnosis (Glomerella cingulata (Stonem.) Spauld \& Schrenk.) del guanábano (Annona muricata L.). Tesis. Universidad de Caldas. Manizales, Colombia.

Ronquist, F., Teslenko, M., van der Mark, P., Ayres, D., Darling, A., Höhna, S., Larget, B., Liu, L., Suchard, M. A., Huelsenbeck, J. P. 2012. MrBayes v. 3.2: efficient Bayesian phylogenetic inference and model choice across a large model space. Systematic Biology. 61 (3): 539-542.

Rueda, K., Saldarriaga, A., Cadavid, G. E., Saldamando, C., Cañas, G. P., Arango, R. 2013. Differential organ distribution, pathogenicity and benomyl sensitivity of Colletotrichum spp. from Blackberry plants in northern Colombia. Journal of Phytopathology. 161 (4): 246-253.

Saldarriaga, A., Castaño-Zapata, J., Arango, R. 2008. Caracterización del agente causante de la antracnosis en tomate de árbol, manzano y mora. Revista Academia Colombiana de Ciencias Exactas, Físicas y Naturales. 32 (123): 145-156.
Sanabria, A., Mahuku, G., Kelemu, S., Cadavid, M. García, C., Hio, J., Martínez, E., Osorio, J. 2010. Molecular identification and characterization of Colletotrichum spp. isolates from Tahiti lime, tamarillo, and mango. Agronomía Colombiana. 28 (3): 391-399.

SAS. 2008. SAS/STAT ${ }^{\circledR 9.2}$ User's Guide, Cary, N C: SAS Institute Inc.

Sharma, G. \& Shenoy, B. D. 2013. Colletotrichum fructicola and C. siamense are involved in chilli anthracnose in India. Archives of Phytopathology and Plant Protection. 47 (10): 1179-1194.

Sreenivasaprasad, S. \& Talhinhas, P. 2005. Genotypic and phenotypic diversity in Colletotrichum acutatum, a cosmopolitan pathogen causing anthracnose on a wide range of hosts. Molecular Plant Pathology. 6: 361-378.

Su, Y. Y., Noireung, P., Liu, F., Hyde, K. D., Moslem, M. A., Bahkali, A. H., Abd-Elsalam, K., Cai, L. 2011. Epitypification of Colletotrichum musae, the causative agent of banana anthracnose. Mycoscience. 52: 376-382.

Than, P. P., Jeewon, R., Hyde, K. D., Pongsupasamit, S., Mongkolporn, O., Taylor, P. W. J. 2008. Characterization and pathogenicity of Colletotrichum species associated with anthracnose on chilli (Capsicum spp.) in Thailand. Plant Pathology. 57: 562-572.

Udayanga, D., Manamgoda, D. S., Liu, X., Chukeatirote, E., Hyde, K. D. 2013. What are the common anthracnose pathogens of tropical fruits? Fungal Diversity. 61 (1): 165179.

Weir, B. S., Johnston, P. R., Damm, U. 2012. The Colletotrichum gloeosporioides species complex. Studies in Mycology. $\mathbf{7 3}$ (1): 115-180.

White, T. J., Bruns, T., Lee, S., Taylor, J. W. 1990. Amplification and direct sequencing of fungal ribosomal RNA genes for phylogenetics. In: PCR Protocols: A Guide to Methods and Application (M.A. Innis, D.H. Gelfand, J.J. Sninsky, J.J. and Y.J. White, editors). Academic Press. San Diego, CA, USA: 315-322. 